Boise State University

ScholarWorks

Mechanical and Biomedical Engineering Faculty

Publications and Presentations

Department of Mechanical and Biomedical

Engineering

6-15-2019

\title{
Work in Progress: First-Year Engineering College Students: Value Created from Participating in a Living/Learning Community
}

\author{
Krishna Pakala \\ Boise State University, krishnapakala@boisestate.edu \\ Kim M.B. Tucker \\ Boise State University, kimtucker@boisestate.edu \\ Samantha Schauer \\ Boise State University
}

Follow this and additional works at: https://scholarworks.boisestate.edu/mecheng_facpubs

Part of the Biomedical Engineering and Bioengineering Commons, and the Mechanical Engineering Commons

Publication Information

Pakala, Krishna; Tucker, Kim M.B.; and Schauer, Samantha. (2019). "Work in Progress: First-Year Engineering College Students: Value Created from Participating in a Living/Learning Community". 2019 ASEE Conference \& Exposition, 26713-1 - 26713-10.

(C) 2019, American Society for Engineering Education, Proceedings of ASEE Annual Conference, Tampa, FL. 


\section{Work in Progress: First-Year Engineering College Students: Value Created from Participating in a Living/Learning Community}

\section{Dr. Krishna Pakala, Boise State University}

Krishna Pakala, Ph.D., is an Clinical Associate Professor at Boise State University, Idaho. His academic research interests include innovative teaching and learning strategies, use of emerging technologies, and mobile teaching and learning strategies.

\section{Ms. Kim M. B. Tucker, Boise State University}

Kim Tucker is currently completing her Doctoral Degree in Curriculum and Instruction and works as the Coordinator of Residential Learning for in the Living Learning Program at Boise State University. Kim's research passions are examining how social learning can lead to impactful learning experiences and a stronger sense of community. Kim is passionate about providing students with opportunities where they can enhance meaningful relationships with their peers, professors, and within their own community.

\section{Samantha Schauer, Boise State University}

Samantha Schauer is a student at Boise State University, graduating in May 2020 with a Bachelor's degree in Mechanical Engineering and a minor in Applied Mathematics. Samantha works as an Undergraduate Research Assistant under Dr. Krishna Pakala. She is also actively involved in the Honors College, the Society of Women Engineers, and the Tau Beta Pi Engineering Honor Society. 


\title{
Work in Progress: First-Year Engineering College Students: Value Created from Participating in a Living Learning Community
}

\begin{abstract}
This Work in Progress paper examines how to capture the perceived value obtained from firstyear engineering college students (FYECS) from participating in the Engineering and Innovation Residential College (EIRC), a living learning community (LLC). People are social by nature and thrive through collaborating and living with others who share similar passions; however, oftentimes FYECS do not have a community of like-minded peers where support, innovation, discourse, and collaboration can take place. Adding to FYECS struggles is the fact that many do not have a mentor in their related field and are unable to start building their professional repertoire, network, technical skills, or their content knowledge related to engineering. Simply put, many FYECS do not identify with a community. The EIRC can be described as a Community of Practice (CoP) where a group of individuals have a shared vision, mutual engagement, shared repertoire, and joint enterprise. The Value Creation Framework, constructed by Wenger, Trayner, and de Laat [1] focuses on assigning value which can be produced through social learning. This theoretical framework can be used as an analytical tool to evaluate the value created within the Community of Practice such as the students living in the EIRC.
\end{abstract}

\section{Introduction}

A Living Learning Community (LLC) is described as a collaborative community within residence halls that intentionally integrates living and learning through classes, programs, and faculty members living in the community. One powerful outcome of an effective LLC is a high quality Community of Practice (CoP). Over the past five years, the Faculty in Residence (FIR) for the Engineering and Innovative Residential College (EIRC) LLC has developed and witnessed the profound benefits for the students who participate in the EIRC. The FIR, Dr. Krishna Pakala, and his family have volunteered to live on campus in the residence halls for the past 5 years. In this important role, the FIR is a 24/7 faculty resource for undergraduate engineering students. The EIRC which will be examined in this project is located at Boise State University in Idaho. The EIRC is about 34\% female and 66\% male, and the distribution of the majors closely mirrors the college of engineering's statistics. The researchers hypothesize that students who live in the EIRC benefit greatly from being a part of the social/academic community.

The EIRC provides many resources to help students adjust to college and get involved on campus. All participants are required to take a course together taught by the FIR, and they meet once a week for the entire year. The first semester students are exposed to an innovative, best practices approach developed by Landis [2] that helps them become self-regulated students. The approach, called the Design Your Process for Becoming a World Class Engineering Student program supports the development of self-regulated learning skills that culminates into a written project at the end of the semester that focuses on goal setting, community building, academic development, and professional development [2]. During the second semester, the EIRC students work in teams on their choice of an engineering problem. The purpose of this course is to 
provide participants in the EIRC with an opportunity to meet on a regular basis to support an active LLC. Together, participants explore aspects of success in engineering through a series of academic, community service, and team building activities. The intended learning outcomes for the engineering LLC are to increase learner self-assurance, confidence in public communication, academic achievement, self-assessment skills, digital fluency, and a sense of belonging to the community and to the university as a whole. The course covers topics such as tips for success in engineering, resume/LinkedIn workshops, how to prepare for college classes, and strategies to help the students develop personally. Providing these resources during a student's first-year, could help the students adjust and prepare for their undergraduate studies.

The FIR of the EIRC has worked in the LLC since Fall 2014 and helped to grow it into a flourishing learning community on campus from a community of 18 to 73 . This FIR has supported close to 350 students over the past 5 years. Fall 2014 was the first time teaching a freshmen class for the FIR, and they had to adjust their teaching style to motivate 18-year-old students. As someone who typically teaches upper-division Mechanical Engineering courses, the FIR had to change their classroom approach in order to work with first-year college students. The class contained several homework assignments which culminated into a final report. The class also had several seminars where faculty members came to the class as guest speakers, and the FIR worked with the career center to host workshops. The EIRC's class was more structured during the first semester.

The second semester was more unstructured, meaning teams were allowed work on their own most times. They were provided feedback on their projects early on in the semester by the senior design instructors. Students also completed various activities which were designed to meet the learning objectives of the LLC as envisioned by the FIR. Student self-confidence was enhanced through service and hands-on building projects. Public communication skills were improved via group social activities and class discussions. A sense of community and belongingness was built when students participated in social activities like game and movie nights and camping and rafting trips. Special events featuring guest-speakers (like the President, Provost, Dean and faculty from the College of Engineering), and attendance at the university's Top Ten Scholars Award (highest academic honor granted to an undergraduate student) ceremony, provided students with professional and academic role models. A couple of cohorts of students were loaned iPads for use during their participation in the LLC in order to facilitate the development of their digital fluency. Students used the iPad in class to interact with the lecture content, as well as to complete assignments and homework.

Along with taking a required course, EIRC participants are required to attend events throughout the semester. The LLC provides opportunities for the students to engage in social activities, events that focus on academic excellence, and events that connect the students to campus and community resources. The students are encouraged to attend career fairs and site visits to businesses in the community, and many of these events are hosted exclusively for the LLC. Roughly six times a semester, the EIRC hosts "Evening with the Faculty,” which allows students to get to know their faculty members outside of the classroom and helps students build relationships with their peers and professors. Other events such as going to a corn maze around 
Halloween, board game nights, and helping with volunteer events are offered to the students in the EIRC. While students are encouraged to attend as many events as they can, they are only required to attend a few per semester. The EIRC is also supported by two Faculty out of Residence, three community assistants, and two resident assistants.

The EIRC has had a profound impact on the FIR and his family. The FIR had a unique opportunity to be a part of the whole student's journey to/from college: from admission/recruitment to graduation/employment. The FIR's family has found an extended family of first-year students who made a positive impact on their overall living experience. A manuscript is in preparation highlighting these experiences from a faculty/family's perspective.

\section{Value of EIRC}

The aim of this Work in Progress paper is to apply a framework where the researchers would be able to examine the perceived value that students obtained from participating in the EIRC. The following research question guides the study: What value is obtained for the students involved in the EIRC LLC? Due to the fact there is limited research on the influence an LLC has on FYECS, this project could help determine how social learning can enhance FYECS educational experiences.

\section{Background}

Social interactions can be classified into two different categories: (a) network; and (b) community. Networks can be defined as a more casual relationship between members of the group where commitment to the group is minimal [3]. An example of networking could be a couple of FYECS talking before class and sharing some resources such as the location of a helpful place to study, the contact information of a professor in the College of Engineering, or the phone number of the math center; however, oftentimes the flow of information stops after the resources have been shared and the group of students do not continue to network after the short interaction. The term community is used to describe a group of individuals who meet often about a shared goal in an enriched manner where information and resources are shared [3]. An example of a community could be a group of FYECS and professors who meet regularly to study, work on projects building robots, or visiting industries related to the engineering field, such as the students who live in an LLC.

LLCs are a great example of a community and can be described as a Community of Practice $(\mathrm{CoP})$ that can be implemented into an academic setting. To be determined a CoP, the group must sustain mutual engagement to pursue enterprise with one another and learning can occur [3]. This building of learning is a significant cornerstone within all CoPs. Shared repertoire is also an essential element to building a CoP and describes the communities' habits, stories, and ways in which doing things become part of the daily routines [3]. Members of a CoP are involved in new activities, can perform new tasks, and are able to master new understandings [3].

LLCs are intended to establish a community of first-year students with similar interests. The transition from K-12 education and living at home to moving on campus for higher education can be a difficult and an unfamiliar change for many students. LLCs aim to make that adjustment 
easier. By participating in an LLC, students are better integrated to their college both academically and socially [4].

It has been found that students who leave the university from their STEM (science, technology, engineering, and math) track are not actually lagging behind their peers academically. Students typically leave STEM due to the heavy curriculum, uninteresting instruction techniques, or a disinterest in the field overall [5]. STEM-focused LLCs help students academically by providing resources, creating study groups, and forming relationships with faculty members and the respective departments/colleges. By providing students with these additional resources and opportunities to work with their peers, LLC participants are better able to overcome those barriers from their coursework, such as the heavy curriculum or uninteresting instruction techniques. The CoP theory finds that individuals learn more through working together, sharing stories, problem-solving, and collaborating with one another, and this may be accomplished when students are in an LLC [3].

One intentional addition to LLCs that distinguishes them from other themed housing options is the integration of faculty into the experience. Faculty members may reside in the community as a FIR, or they may locate their office within the residential college [6]. Students who participate in LLCs are also shown to have more interaction with faculty members outside of the classroom and are more likely to form a mentorship relationship with a faculty member [7].

While in general, transitioning to higher education and studying engineering is difficult for most students, it can be especially hard for first-generation college students, women, and minority groups. It was found that while $82 \%$ of students whose parents earned at least a bachelor's degree enrolled in college, only 54\% of students whose parents only completed high school enrolled directly after completing high school [4]. It can be especially difficult for firstgeneration students to succeed in college because they don't have the same resources as many of their peers do, for example, understanding how to fill out the necessary forms, such as the FAFSA. It was found that first-generation students who participated in an LLC experienced a smoother academic and social transition to their university than first-generation students living in traditional on-campus housing [4].

LLCs are also an effective mechanism to support women pursuing STEM degrees [5]. Women are underrepresented in engineering. In 2013 only 19.20\% of undergraduates enrolled in engineering fields were female [8]. While women typically earn higher grade point averages, they actually have lower levels of confidence than their male counterparts and are less confident in their engineering abilities [7]. LLCs can help alleviate that gap by connecting women with resources to help them succeed and additionally connect them to female faculty members and mentors who can support them during their undergraduate career and beyond [9]. Minority groups are also likely to benefit from participating in an LLC. In 2013, 37.29\% of undergraduate engineering students were not Caucasian [8]. LLCs do not have to specifically target one group, however, engineering LLCs that target minority groups have a higher retention rate than LLCs that are open to the general engineering population [10]. 


\section{Framework}

The Value Creation Framework, constructed by Wenger, Trayner, and de Laat would be used as the theoretical framework to analyze the value created within the CoP [1]. The Value Creation Framework focuses on assigning value which can be produced through social learning such as the learning which takes place for FYECS living in the EIRC. The Value Creation Framework has five cycles [1]:

- Cycle 1: Immediate value: Activities and interactions. The most basic cycle of value creation considers networking/community activities and interactions sparking the interest of the individual.

- Cycle 2: Potential value: Knowledge capital. Activities and interactions can produce "knowledge capital" when the value is realized at a later date and time.

- Cycle 3: Applied value: Changes in practice. Adapting and applying knowledge capital that leads to change in practice, approaches, or protocol.

- Cycle 4: Realized value: Performance improvement. After applying the knowledge capital, reflection on what effects the application of knowledge capital had on the members practice is taken into consideration.

- Cycle 5: Reframing value: Redefining success. Value creation is achieved when social learning causes a reconsideration of the learning imperatives and the criteria by which success is defined. This includes reframing strategies, goals, or redefining success at an individual, collective, or organizational level.

\section{Case study for applying the framework}

One example of value-creation from participating in an LLC would be that of an engineering student who chooses to live in an LLC their first year of college. By simply joining the LLC, meeting some of their peers, and having fun, they have achieved Cycle 1: Immediate Value. In order to reach Cycle 2: Potential Value, that student would have to continue to work on a mutually beneficial relationship with the people they have met. That could involve studying together and sharing ideas, and study groups can easily be formed in an LLC because the students are all studying similar topics and taking many of the same classes. By studying together, those students would understand the topics at a deeper level and develop good study groups which could raise the academic level of all participants.

Cycle 3: Applied Value is a more difficult phase to reach. One way a FYECS could reach this stage would be through interacting with the LLC's FIR. For example, let us assume that the FYECS started to engage in group study sessions that the FIR was holding during the semester. As the result of the interactions, the FIR and the FYECS form a mentorship. That faculty member would then be able to better connect the FYECS to resources at the university and open up doors for other opportunities which may include research. They could even begin to conduct research together, which provides the student with a new skill set and experience that was not previously available to them as a FYECS. This opportunity may have not have occurred in the same way without the FYECS participation in the LLC. 
If that student and faculty member continued to do research, the student would acquire new skills that they had not yet uncovered. For example, through the mentorship established by the FIR and the FYECS, the two may continue to work more on a research project with one another. The research project could be written about ways to properly implement engineering education techniques into the classroom. The student and faculty member may choose to publish their findings. The FYECS reflects back on the skills gained through working on the research and find they are now more hirable. The FYECS has now entered Cycle 4: Realized Value. By publishing their work, they have actually produced something due to their relationship that had not previously been done. In order to reach Cycle 5: Reframing Value, their work would have to create institutional change. If their work was on engineering education techniques, and other faculty in the college or the university decide to implement changes to their teaching routines, then the work of that student contributed to major change that affects the entire university. To simply publish work is not enough to reach Cycle 5 of value-creation. There must be institutional change that occurs as the result of the realized value.

\section{Plans for Data Collection and Analysis}

To perform this study in the near future, we would use mixed methods to obtain data on how a FYECS can obtain value from living in the EIRC LLC located at Boise State University. This study will be conducted with the goal of learning how working with a LLC can create value for the FYECS through using Wenger et al.'s Value Creation Framework [1]. Through the use of the Value Creation Framework, the researchers will provide a foundation for the evaluation process where the integration of heterogeneous sources of data will help to create a picture of how networks or communities can potentially create value for the FYECS [1].

For this study, purposeful sampling will be employed “...based on the assumption that the investigators want to discover, understand, and gain insight and therefore must select a sample from which the most can be learned” [11]. Additionally, criterion-based sampling will be used for the selection of the participants in this study [12]. This method will be used to select the participants because the individuals meet the predetermined criteria [13] for the research project. The predetermined criteria will be 1) the participants live or has lived in EIRC LLC and 2) the participant is or was enrolled in the LLC Engineering Course.

\section{Interviews}

A percentage of the participants who have lived in the EIRC LLC will be interviewed based on questions adapted from the template created from the Value Creation Framework [1]. Each interview will be conducted at the university in the researchers' offices or at a quiet location such as a public library. The interviews will be digitally recorded, and each interview will be conducted in a semi-structured manner [14]. The interviews will last approximately 45 minutes.

\section{Personal Value Narrative Form}

The Personal Value Narrative Form created by Wenger et al. which was developed from their Value Creation Framework [1] will be given to a percentage of the participants to describe their overall experience of participating in the LLC. The Personal Value Narrative Form would be 
used to help produce a robust picture of the contributions of the participant's time spent living in the LLC. The following guiding questions will be asked [1]:

1. What activities did you participate in as the result of the LLC?

2. What specific insights did, or didn't you gain from participating in the EIRC LLC?

3. How did the LLC influence you as a FYECS? What did or didn't it enable you to do that would not have happened otherwise?

4a. What difference did it make to your performance in school? How did this contribute to your personal/professional development?

4b. How did the LLC contribute to the goal of the organization? Qualitatively? Quantitatively? 5. Has the LLC changed your or some other stakeholders' understanding of what matters?

\section{Course Evaluations and First Semester Written Project}

The researchers will collect current and past course evaluations submitted by the FYECS who participate in the LLC course. Course evaluations are distributed by the University for all courses each semester. The evaluation period is open for the last two weeks of a semester, closing the night before finals week. Periodically, reminder emails are sent to students who have not yet finished their evaluations to encourage them to complete the evaluations and to remind them of the importance of student feedback for the instructors and for the university. The instructor does not have access to course evaluation responses until after final grades are submitted and the grades are officially posted by the Registrar. Student responses are entirely anonymous. The system only reports how many students completed the course evaluations and their responses. In order to encourage maximum participation and solicit feedback from the students, the instructor did offer an extra credit incentive to students who provided a screenshot of their survey completion. The screenshots do not include survey responses, they just show a confirmation of their course evaluation submission. The written projects completed in the first semester of the LLC course will also be used in the study by obtaining prior permission from the students. All data would be analyzed through the lens of the five cycles of the Value Creation Framework.

\section{Discussion and Conclusion}

The reviewed literature suggests LLCs provide great benefits to students [3, 4]. Especially, the LLCs have a huge positive impact on first-generation students [4]. The EIRC with 34\% female students, supports the literature that LLCs provide pathways to support women pursuing STEM degrees [5, 9]. Retention of underrepresented students can be achieved by focused attention to design and recruitment in the LLCs [10].

Our study was guided by the research question: What value is obtained for the students involved in the EIRC LLC? A framework that helps assess the value created in the EIRC for FYECS is identified [1]. This framework is ideally suited for the EIRC owing to the varied experiences the FYECS are exposed to in the program. A case study was provided as to how one might apply the framework. In this Work in Progress paper, a process to carry this research is also identified. 
In the near future, this exploratory study will be further advanced by obtaining the Institutional Review Board approval to carry out the research with human subjects. The researchers hope to quantify the value generated for the students by participating in the EIRC to further bolster the support for this program. The dissemination of the results may encourage participants to continue in their value creation after they leave the EIRC.

Once the results from this study are obtained and analyzed, the future work of the researchers involves answering another research question: How do we translate the value proposition to students who are not part of a community of practice? Translating some of the best practices in the EIRC to students who are not part of it will surely impact the recruitment and retention efforts. Quantifying the value of these experiences can provide guidance for support systems that can be put in place by the university.

\section{References}

[1] E. Wenger, B. Trayner and M. de Laat, Promoting and assessing value creation in communities and networks: a conceptual framework. Open University of the Netherlands, 2011.

[2] R. Landis, Studying engineering: A road map to a rewarding career, Discover Press, 1995.

[3] E. Wenger, Communities of practice, 1st ed. Cambridge: Cambridge University Press, 1999.

[4] K. Inkelas, Z. Daver, K. Vogt and J. Leonard, "Living-Learning Programs and FirstGeneration College Students' Academic and Social Transition to College", Research in Higher Education, vol. 48, no. 4, pp. 403-434, 2006. Available: 10.1007/s11162-006-9031-6 [Accessed 17 December 2018]

[5] J. Micomonaco, "Living-Learning Communities as a Potential Intervention to Increase the Retention of First-Year Engineers", ASEE, 2011.

[6] K. Inkelas, M. Soldner, S. Longerbeam and J. Leonard, "Differences in Student Outcomes by Types of Living-Learning Programs: The Development of an Empirical Typology", Research in Higher Education, vol. 49, no. 6, pp. 495-512, 2008. Available: 10.1007/s11162-008-9087-6 [Accessed 28 December 2018].

[7] M. Soldner, H. Rowan-Kenyon, K. Inkelas, J. Garvey and C. Robbins, "Supporting Students' Intentions to Persist in STEM Disciplines: The Role of Living-Learning Programs Among Other Social-Cognitive Factors", The Journal of Higher Education, vol. 83, no. 3, pp. 311-336, 2012. [Accessed 28 December 2018].

[8] "Data Tables - nsf.gov - Women, Minorities, and Persons with Disabilities in Science and Engineering - NCSES - US National Science Foundation (NSF)", Nsf.gov, 2019. [Online]. Available: https://www.nsf.gov/statistics/2017/nsf17310/data.cfm. [Accessed: 02- Feb- 2019] 
[9] W. Frazier and M. Eighmy, "Themed Residential Learning Communities: The Importance of Purposeful Faculty and Staff Involvement and Student Engagement", The Journal of College and University Student Housing, vol. 38, no. 2, pp. 10-31, 2012. [Accessed 29 December 2018].

[10] J. Everett and M. Flynn, "Engineering Learning Communities: - USA National Survey 2012", in 120th ASEE Annual Conference \& Exposition, Atlanta, GA, 2013.

[11] S. Merriam and E. Tisdell, Qualitative research: A guide to design and implementation, 4th ed. San Francisco: Jossey Bass. pp. 105, 2016.

[12] J. Goetz and M. LeCompte, Ethnography and qualitative design in educational research. New York: Academic, 1984.

[13] M. Patton, Qualitative evaluation and research methods, Thousand Oaks, CA: Sage, 1990.

[14] K. Roulston, Reflective interviewing: A guide to theory and practice. Los Angeles: Sage Publications, 2010. 